\title{
The impact of future climate change on West African crop yields: What does the recent literature say?
}

\author{
Philippe Roudier ${ }^{\mathrm{a}, *}$, Benjamin Sultan $^{\mathrm{b}}$, Philippe Quirion ${ }^{\mathrm{c}}$, Alexis Berg ${ }^{\mathrm{b}}$ \\ ${ }^{a}$ CIRED, 45 bis av de la Belle-Gabrielle, 94736 Nogent-sur-Marne, France \\ ${ }^{\mathrm{b}}$ IRD - LOCEAN/IPSL, Laboratoire d'Océanographie et du Climat: Expérimentation et Approche Numérique - UMR 7159 (CNRS/IRD/UPMC/MNHN) - Université Pierre \\ et Marie Curie, Case 100, 4 Place Jussieu, 75252 Paris cedex 05, France \\ ${ }^{\mathrm{c}}$ CIRED, CNRS, LMD-IPSL, France
}

\section{A R T I C L E I N F O}

\section{Article history:}

Received 19 August 2010

Received in revised form 23 March 2011

Accepted 4 April 2011

Available online 19 May 2011

\section{Keywords:}

West Africa

Agriculture

Climate change

Forecast

Crop model

Yield

\begin{abstract}
A B S T R A C T
In West Africa, agriculture, mainly rainfed, is a major economic sector and the one most vulnerable to climate change. A meta-database of future crop yields, built up from 16 recent studies, is used to provide an overall assessment of the potential impact of climate change on yields, and to analyze sources of uncertainty.

Despite a large dispersion of yield changes ranging from $-50 \%$ to $+90 \%$, the median is a yield loss near $-11 \%$. This negative impact is assessed by both empirical and process-based crop models whereas the Ricardian approach gives very contrasted results, even within a single study. The predicted impact is larger in northern West Africa (Sudano-Sahelian countries, $-18 \%$ median response) than in southern West Africa (Guinean countries, -13\%) which is likely due to drier and warmer projections in the northern part of West Africa. Moreover, negative impacts on crop productivity increase in severity as warming intensifies, with a median yield loss near $-15 \%$ with most intense warming, highlighting the importance of global warming mitigation.

The consistently negative impact of climate change results mainly from the temperature whose increase projected by climate models is much larger relative to precipitation change. However, rainfall changes, still uncertain in climate projections, have the potential to exacerbate or mitigate this impact depending on whether rainfall decreases or increases. Finally, results highlight the pivotal role that the carbon fertilization effect may have on the sign and amplitude of change in crop yields. This effect is particularly strong for a high carbon dioxide concentration scenario and for C3 crops (e.g. soybean, cassava). As staple crops are mainly C4 (e.g. maize, millet, sorghum) in WA, this positive effect is less significant for the region.
\end{abstract}

(๖ 2011 Elsevier Ltd. All rights reserved.

\section{Introduction}

The Fourth Assessment Report (AR4) of the Intergovernmental Panel on Climate Change (IPCC, 2007) has, with greater confidence than previous reports, warned the international community that the increase in anthropogenic greenhouse gases emissions will result in global climate change. Associated with the expected global temperature rise, precipitation patterns and quantities will likely change, and the frequency and intensity of major natural hazards, such as droughts, heat waves, floods and fires are expected to increase.

Although many uncertainties remain in the regional projections of these changes - particularly in the Tropics (Douville, 2008) local water resources, natural and agricultural ecosystems, and

\footnotetext{
* Corresponding author. Tel.: +33 143947367; fax: +33 143947370.

E-mail address: roudier@centre-cired.fr (P. Roudier).
}

therefore human societies are expected be significantly impacted. These impacts are likely to be particularly severe in developing countries, where poor communities are highly dependent on the direct use of local natural resources, and where widespread poverty limits the capacity to cope with climate variability and natural disasters (Commission of the European Communities, 2007). Among these regions, Africa is considered particularly vulnerable to climate change, due to a combination of naturally high levels of climate variability, high reliance on climate sensitive activities, such as rainfed agriculture, and limited economic and institutional capacity to cope with, and adapt to, climate variability and change. Furthermore, under its current climate Africa is already facing recurrent food crises and water scarcity which are exacerbated by rapid population growth: climate change will thus act as an additional stress in the future of African economies and livelihood (CGIAR, 2009).

Agriculture is certainly the most vulnerable sector in SubSaharan Africa (SSA). Crop yields are highly dependent on climate 
fluctuations, as agriculture is mostly rainfed (96\% of all agricultural land, World Bank, 2008). Moreover, crop management (use of fertilizers and pesticides combined with modern cultivars) remains low (Dingkuhn et al., 2006). Adverse changes in climate are thus likely to directly impact agricultural systems, thereby threatening food security and economic growth. Indeed in 2000, approximately $80 \%$ of all cereals consumed in SSA were supplied by domestic production and, in recent years, agriculture's share in SSA's GDP has varied between 15 and 20\% (World Bank, 2008). It is, therefore, crucial to diagnose the potential implications of climate change on crop productivity in the coming decades. However, producing reliable future agricultural production scenarios remains challenging because of large uncertainties in regional climate change projections, in the response of crops to environmental change (rainfall, temperature, $\mathrm{CO}_{2}$ concentration), in the coupling between climate models and crop productivity functions, and in the adaptation of agricultural systems to progressive climate change (Challinor et al., 2007). These uncertainties result in diverging estimations of productivity response to climate change in SSA in the recent literature. Thus there is clearly a need for a comprehensive overview of climate change impacts on agriculture in the different regions of Africa.

The objective of this study is to provide such an overview for West Africa, based upon the recent scientific literature (ECOWAS countries + Cameroon). This region, particularly vulnerable to climate variability and changes, concentrates a significant part of SSA's population and croplands: $43 \%$ of the population, ${ }^{1}$ around $53 \%$ of the area of cereals, roots and tuber crops (FAOSTAT). Rainfall in this region depends on the West African monsoon (WAM), which takes place during the boreal summer as a result of differential warming over the ocean (the Gulf of Guinea) and the land surface. The WAM exhibits considerable variability on interannual and interdecadal timescales: the long-term and large-scale drought of the 70s and 80s (e.g. Dai et al., 2004) stands as the greatest regional climatic signal over the second half of the last century in terms of precipitation (Trenberth et al., 2007). Naturally, such variability has had dire consequences for local populations - highlighting their vulnerability to potential adverse future changes of the WAM in the context of global climate change. Furthermore, there are few consensuses regarding the evolution of monsoon rainfall in a warmer climate: some studies make projections of wetter conditions and some predict more frequent droughts (Druyan, 2010). To our knowledge, only two recent studies (Biasutti, 2009; Patricola and Cook, 2010) found a robust agreement across the various climate models of the IPCC CMIP3 ensemble on the seasonal distribution of Sahel rainfall changes (with a drying of the early season and positive rainfall anomaly at the end) in contrast with a large uncertainty for summertime rainfall totals.

This study aims to explore beyond a simple static review of the literature: we build a meta-database of future yield change by compiling results from 16 published papers dealing with climate change impacts on agriculture in West Africa. From this database, we are therefore able to provide a quantitative assessment of the range of projected impacts and an analysis of the sources of uncertainty. Given the range of regions, crops and methodologies encompassed by the different studies, such a meta-analysis is bound to remain imperfect. However it is a necessary first step to identify the main causes of uncertainty in agricultural future projections in the region, and a fundamental prerequisite to produce reliable assessments (Challinor et al., 2009).

\footnotetext{
${ }^{1}$ http://www.oecd.org/document/19/

0,3343,en_38233741_38246806_38283987_1_1_1_1,00.html.
}

\section{Materials and methods}

\subsection{The general workflow}

An examination of the literature on climate change impacts on agriculture in Africa, and elsewhere in the world, reveals a typical workflow summarized in the flowchart of Fig. 1. Quantifying the response of crop yields to climate change requires the following main steps.

\subsubsection{Generation of future climate}

To assess the impact of climate change on crop production within a given study domain, it is necessary to define scenarios describing the future evolution of meteorological variables. The simplest way is to define a uniform scenario (for instance $+10 \%$ in rainfall, $+2.5{ }^{\circ} \mathrm{C}$ in temperature) and to add these changes to the observed climate data of a present time period. Among the studies reviewed in the present analysis, a few follow that approach: Ben Mohamed et al. (2002), Salack (2006) and Vanduivenbooden et al. (2002). However, it is obvious that such a method, although allowing useful sensitivity studies, relies on assumptions about future climate: it has no real physical basis, and does not preserve consistency among climate variables. A more physics-based approach is the use of global climate models (GCMs) that are able to generate physically consistent sets of climate variables over the study domain. These models are forced by scenarios of future radiative forcing, e.g. increasing greenhouse-gas (GHG) concentrations. Several emissions scenarios, describing different future socio-economic evolutions, have been defined by the IPCC, and for a given scenario different GCMs can provide different climate projections over the study area. Therefore, in order to span some of the uncertainty in climate projections, the majority of the published papers use several GCMs and/or scenarios; see for instance Schlenker and Lobell (2010) in this review.

\subsubsection{Crop modelling}

To translate climate scenarios into possible agricultural outputs, two distinct approaches are usually adopted: statistical modelling and process-based crop modelling, both of which aim at estimating crop productivity as a response to climate.

Empirical crop models are statistical relationships derived from observations, linking crop yields in a given location to local climate variables. Although such relationships are relatively easy to compute, calibrating and validating a robust statistical model requires long series of data (yields and climate). One advantage is that such relationships can be established directly at large scale (e.g. national) using spatially aggregated climate variables to predict average yields over large areas. In this review, Lobell et al. (2008) and Schlenker and Lobell (2010) in particular, follow this approach, arguing that it provides a straightforward assessment of future climate impacts at a scale directly relevant to informing policymakers and stakeholders.

The other approach is process-based crop modelling. These models represent the physiological processes of crop growth (assimilation of carbon and nutrients, transpiration) and development (e.g. apparition of successive organs, vegetative and reproductive phases) as a response to climate, thus simulating the seasonal crop cycle and its different parts. Because this approach allows, in theory, the capture of detailed, intraseasonal and non-linear effects of climate on crops, most climate impact studies use a mechanistic crop model, as can be seen in the present review (see Table 1) Not all models, however, have the same physiological approach, nor go into the same level of detail. In particular, the positive effect of higher atmospheric $\mathrm{CO}_{2}$ concentrations on crop photosynthesis (Tubiello et al., 2007b) is not taken into account in all crop models (for example, Salack, 2006). In addition, these models usually require numerous parameters and 


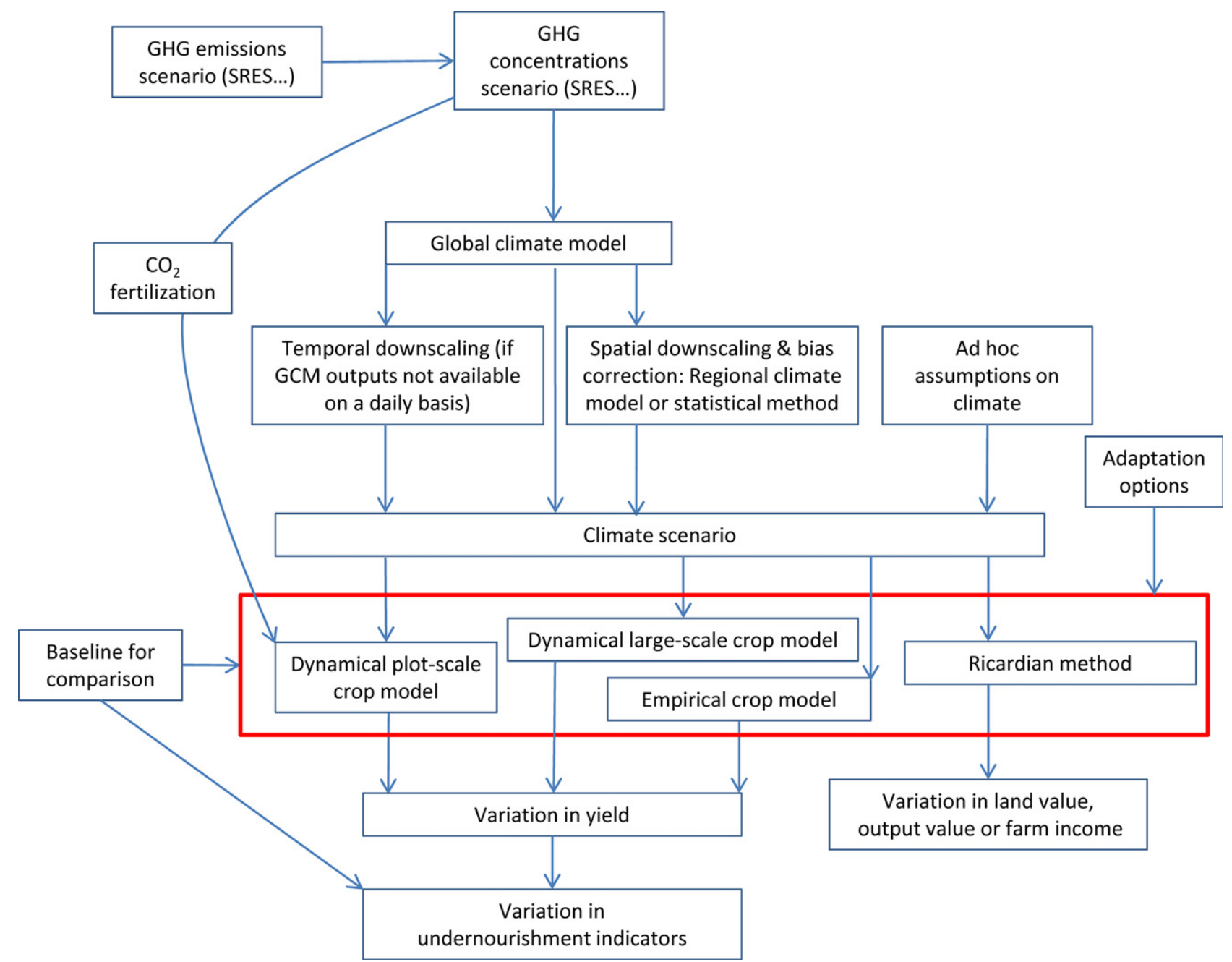

Fig. 1. Summarized workflow to predict future agricultural production.

are thus applied at the plot scale where these data are available and can be considered homogeneous: they do not directly provide information on climate impacts at larger scale.

Note that a third approach, the Ricardian analysis (Mendelsohn et al., 1994), is also used for estimating the impact of climate change on agriculture in West Africa (e.g. Kurukulasuriya and Mendelsohn, 2007; Molua, 2009). This approach focuses on the net income of farming systems instead of focusing on crop yields and, unlike most impact studies, takes adaptation strategies (cropping system management) into account.

\subsubsection{Linking GCMs and crop models}

Combining GCM and crop models raises several issues. First, GCM most often show significant biases in their simulated climate: regional amounts and patterns of precipitation, in particular, may not be realistic (Randall et al., 2007). Hence, geographically explicit climate impact studies generally require some level of climate data bias correction. The simplest correction method is the "anomaly method": for a given GCM, a computed mean annual anomaly between future and current simulated climates is added to a current, observation-based, climate dataset. In the present review, Müller et al. (2010) for instance, adopt this approach.

Second, combining GCM and mechanistic crop models is more complex than a simple coupling of the two models due to scale mismatch. Indeed, GCMs typically produce climate projections at a spatial resolution in the order of $2^{\circ}$. While statistical crop models can be directly calibrated to use such aggregated information as input (see previous section), process-based crop models, being designed to work at plot scale, need climate data at a finer spatial scale. Thus, there is, in general, a need to downscale the climate information from the GCM to the crop model scale. Temporal downscaling may also be required when the outputs of the GCM are only available at monthly intervals, for example, for some IPCC AR4 simulations archived by the Program for Climate Model Diagnosis and Intercomparison, PCMDI (see http://www-pcmdi.llnl.gov/ipcc/data_status_tables.htm). There are two general types of downscaling methods (that can be sometimes combined):

- Statistical downscaling, in which empirical relationships between atmospheric meso-scale circulation and local climate are used to retrieve realistic time series of local climate variables. This method includes stochastic weather generators, linear or non-linear regressions, weather-type methods (Zorita and von Storch, 1999; Müller et al., 2010), for instance, use a stochastic weather generator to downscale monthly climate variables to an hourly (??) time step.

- Dynamical downscaling, which uses regional climate models with a fine (approximately $10-50 \mathrm{~km}$ ) resolution nested in the GCM (Paeth et al., 2011). It has to be noted, however, that in the impact studies reviewed here, the type of downscaling method - if any - is not systematically reported or clearly detailed.

In recent years, the growing need for climate changeoriented crop modelling applications has led to the development 
Table 1

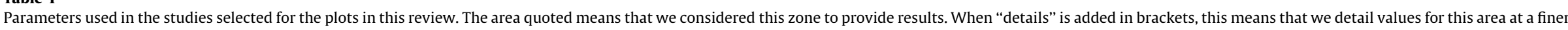
scale. WA: West Africa, SSA: Sub Saharan Africa.

\begin{tabular}{|c|c|c|c|c|c|c|c|c|}
\hline Reference & Climate model & Crop model & Scenario & Area & Horizon & Crop & C. Fert & Baseline \\
\hline Adejuwon (2006) & HadCm2 & EPIC & $1 \% /$ year in $\mathrm{CO}_{2}$ & Nigeria & $2035 / 2055 / 2085$ & Cassava, maize, millet, rice, sorghum & Yes & $1960 / 1990$ \\
\hline Ben Mohamed et al. (2002) & MAGICC+SCENGEN & Empirical & $\begin{array}{l}-10 \% \text { rain; }+10 \% \text { tempe } / / \\
-20 \% ;+20 \%\end{array}$ & Niger & 2025 & Millet & No & $1968 / 1998$ \\
\hline Butt et al. (2005) & $\mathrm{HadCm}, \mathrm{CGCM}$ & $\begin{array}{l}\text { EPIC+ PHYGROW } \\
+ \text { NUTBAL }\end{array}$ & $\begin{array}{l}\text { Greenhouse gases } \\
\text { integrations }\end{array}$ & Mali & 2030 & $\begin{array}{l}\text { Cotton, cowpea, groundnut, maize, } \\
\text { millet, sorghum }\end{array}$ & Yes & $1960 / 1991$ \\
\hline Fischer et al. (2005) & $\begin{array}{l}\text { HadCm3, CSIRO, } \\
\text { CGCM2, NCAR }\end{array}$ & $\mathrm{AEZ}+\mathrm{BLS}$ & A2 & SSA & 2080 & Global & Yes & $1961 / 1990$ \\
\hline Nelson et al. (2009) & NCAR, CSIRO & IMPACT+DSSAT & A2 & SSA & 2050 & $\begin{array}{l}\text { Global, maize, millet, rice, sorgum, } \\
\text { wheat, soybean, groundnut }\end{array}$ & Yes/no & 2000 \\
\hline Jones and Thornton (2003) & HadCM2 & CERES - maize & Not found & WA (details) & 2055 & Maize & No & $\begin{array}{l}\text { "1990 climate } \\
\text { normals" }\end{array}$ \\
\hline Liu et al. (2008) & HadCM3 & GEPIC & A1FI, B1, A2, B2 & SSA, WA (details) & 2030 & $\begin{array}{l}\text { Global, cassava, maize, millet, rice, } \\
\text { sorghum, wheat }\end{array}$ & Yes & 1990/1999 \\
\hline Lobell et al. (2008) & 20 GCMs & Empirical & $\mathrm{A} 1 \mathrm{~B}, \mathrm{~A} 2, \mathrm{~B} 1$ & WA & 2030 & $\begin{array}{l}\text { Cassava, groundnut, maize, millet, } \\
\text { rice, sorghum, wheat, yams }\end{array}$ & No & $1998 / 2002$ \\
\hline Müller et al. (2010) & $\begin{array}{l}\text { CCSM3 + ECHAM5 } \\
+ \text { + ECHO - G } \\
+ \text { GFDL + HADCM3 }\end{array}$ & LPJmL & $A 1 B+A 2+B 1$ & WA & 2050 & Global & Yes/no & $1996 / 2005$ \\
\hline Paeth et al. (2008) & REMO & MOS (empirical) & B2 & Benin & $2025 / 2020$ & $\begin{array}{l}\text { Beans, cassava, cotton, groundnut, } \\
\text { maize, rice, sorghum, yams }\end{array}$ & No & $1979 / 2003$ \\
\hline Parry et al. (2004) & HadCM3 & Empirical + BLS & $\begin{array}{l}\text { A1FI, A2A, A2B, A2C, } \\
\text { B1A, B2A, B2B }\end{array}$ & WA & $2020 / 2050 / 2080$ & Global & Yes/no & 1990 \\
\hline Salack (2006) & Scenario & DSSAT 4 & $\begin{array}{l}\left(+1{ }^{\circ} \mathrm{C},+1.5^{\circ} \mathrm{C},+3^{\circ} \mathrm{C}\right) /(+5 \%, \\
+10 \%,+20 \%)\end{array}$ & Niger/Burkina & $2020 / 2050 / 2080$ & Millet mtdo/zatib, sorghum & No & $1961 / 1990$ \\
\hline Schlenker and Lobell (2010) & 16 GCMs & Empirical & A1B & WA (details) & 2055 & $\begin{array}{l}\text { Cassava, groundnut, maize, } \\
\text { millet, sorghum }\end{array}$ & No & $1960 / 2002$ \\
\hline Smith et al. (1996) & CCCM, GFD3, GISS & DSSAT 3 & $2 * \mathrm{CO}_{2}$ & Gambia & 2075 & $\begin{array}{l}\text { Groundnut, maize, millet late, } \\
\text { millet early }\end{array}$ & Yes & $1951 / 1990$ \\
\hline Tingem and Rivington (2009) & GISS, HadCM3 & Cropsyst & A2, B2 & Cameroon & $2020 / 2080$ & $\begin{array}{l}\text { Bambara nut, groundnut, maize, } \\
\text { sorghum, soybean }\end{array}$ & Yes & $1961 / 1990$ \\
\hline Vanduivenbooden et al. (2002) & MAGICC+SCENGEN & Empirical & $\begin{array}{l}-10 \% \text { rain; }+10 \% \text { temp } / / \\
-20 \% ;+20 \%\end{array}$ & Niger & 2025 & Cowpea, groundnut & No & $1968 / 1998$ \\
\hline
\end{tabular}


of large-scale crop modelling. Such models are designed and calibrated to work directly at a scale compatible with climate model outputs, suppressing the need for downscaling/upscaling. Some models are developed independently as climate impact models (Challinor et al., 2004; Tao et al., 2009), and others are developed as part of Earth System vegetation models in which they account for croplands (De Noblet-Ducoudré et al., 2004; Bondeau et al., 2007; Berg et al., 2011); they may then be used for climate impact studies. In the present review, Müller et al. (2010) use such a model, LPJ-ml (Bondeau et al., 2007).

\subsubsection{Adaptation to climate change}

When assessing the impact of climate change on yields it is important to know if the studies take adaptation into account. According to Chuku and Okoye (2009), the adaptation options available in agriculture to cope with climate change can be classified as (i) income/asset management, (ii) government programs and insurance, (iii) farm production practices and (iv) technological development. These authors also underline that these categories are characterized by the scale and the agents involved. Several adaptation options are already used at the local scale by Sahelian farmers. They are generally farm production practices (e.g. water management, selection of crop landraces, fertilization) but also income/asset management (e.g. diversification of activities, migrations). This shows that adaptation is a fundamental issue in assessing future crop yield scenarios if one wants to avoid an overestimation of climate change impacts.

However, in most of the papers selected in this review, adaptation is not explicitly taken into account. In some studies (e.g. Müller et al., 2010) the sowing date changes every year but is still based on the same general cropping practice (e.g. sowing at the first big rain) so this behavior is an existing adaptation to the interannual variability of climate rather than to climate change. Tingem and Rivington (2009) simulate the yield change with and without adaptation. They consider new sowing dates and hypothetical improved cultivars. Future yield losses are clearly limited by these adaptation options. Butt et al. (2005) present their results, both without adaptation, and with a set of theoretical adaptation options: crop mix, heat resistant varieties and economic. All of them definitely improve future potential yields. Note that for these two studies, we only include values without the adaptation options in the database because, (i) some of these options are hypothetical and (ii) we try to focus more on the raw impact of climate. Finally, the Ricardian studies consider full adaptation. However, it is not possible in the results to detail what options are used and the impact of climate change without adaptation. Moreover, this method assumes out the costs of the transition from one climate to another, hence it over-estimates the benefits of adaptation.

Globally, the selected assessments assume out many adaptation practices that could be used in the future and focus more on the "gross" impact of climate on yields.

\subsection{The meta-database}

Our literature survey covers major publications on the impact of climate change on crop yields in West Africa. Only studies where the relative yield change between the present and the future was reported as numerical or graphical data, or was available by personal communications, were included. The Ricardian analyses were not considered since they only deal with the net output/ income value, and future yields are not available. Results from Ricardian studies are therefore presented separately in Section 3.6. It should be noted that the reference time period can vary slightly from one paper to another (1961-1990 for Tingem and Rivington, 2009 and 1960-2002 from Schlenker and Lobell, 2010, for example): this non-negligible impact on results is presented as variations. Overall we used 16 papers to build the meta-database (Table 1). We extracted the relative yield change for each area and each scenario (sometimes several scenarios, countries and/or several crops per study). We also tried to avoid an overrepresentation of any individual study. More precisely, we randomly deleted half of the values from Schlenker and Lobell (2010), initially representing one third of the meta-database. Finally, we retained 347 values of relative yield change from the 16 studies. The contribution of each study to the meta-database is given in supplementary material.

We were specifically interested in finding generic explicative variables that might influence the magnitude and/or sign of the response of the yield to climate change. We therefore selected and categorized 5 variables:

- The $\mathrm{CO}_{2}$ fertilization effect: We defined two categories depending on whether the fertilization effect is taken into account in the yield projection. The category taking account of the $\mathrm{CO}_{2}$ effect regroups 157 of 347 points, while neglecting the $\mathrm{CO}_{2}$ effect regroups 190 values.

- The intensity of the warming scenario: We deducted the radiative forcing from the SRES scenario and the time horizon according to the table published by the IPCC (http://www.grida.no/publications/other/ipcc_tar/?src=/climate/ipcc_tar/wg1/551.htm). It should be noted that this variable can be found only for studies considering the SRES scenarios ( 10 of 16 studies and 221 points of 347). We then defined two categories according to the median value, which divides the sorted data set into two equal parts so that each part represents half of the sampled population. The median value of the radiative forcing is $3.9 \mathrm{~W} / \mathrm{m}^{2}$ which corresponds roughly to an increase of $3{ }^{\circ} \mathrm{C}$ in the global temperature.

- The yield modelling category: Two categories are defined according to the general workflow presented in Section 2.1: statistical crop modelling studies (149 points of 347) and process-based crop modelling studies (198 points of 347).

- The crop type: The selected papers generally consider food crops (mainly maize, millet and sorghum). Since very few authors (Smith et al., 1996; Salack, 2006) give details of the cultivars used, only the name of the crop type is retained in the metadatabase. Some papers give results by grouping several crop types ("major crops" for Müller et al., 2010; "cereals" for Fischer et al., 2005) and are categorized together as "global" in the metadatabase.

- The area: Some of these studies present results aggregated at the continent (Sub-Saharan Africa; SSA) or sub-continent scale (West Africa; WA) and some others consider a specific country. We divided the latter into two categories according to the climatic gradient: the Sudano-Sahelian area regrouping Niger, Mali, Burkina Faso, Senegal and Gambia (126 points of 347) and the Guinean area regrouping Benin, Togo, Nigeria, Ghana, Liberia, Sierra Leone, Cameroon, Guinea, Guinea Bissau, Ivory Coast (101 points of 347).

Other descriptive variables are available in the meta-database (Table 1): the name of the climate model used for future projections, the time period for the present climate, the time horizon for future scenarios, the name of the process-based crop model used for projections.

\subsection{The meta-analysis methodology}

Quantifying the impact of climate change on agricultural yields requires a methodology with nested components (described in Section 2.1) where the choice of any individual component (for instance the choice of the climate model and/or the crop model) 
and the way they are coupled together (for instance the choice of the downscaling technique) can strongly influence the results. We use the meta-database combining results from 16 published papers to sample the structural uncertainty of the response of the yield to climate change in Africa. Histograms of relative yield change between present and future are one way to visually assess the most frequent changes and the dispersion of responses within the literature. These histograms of yield change can be drawn not only for the whole dataset but also for sub-samples based on the categorical explicative variables defined in Section 2.2. The differences between the yield change distributions of sub-samples, defined on the basis of an explicative variable, can illustrate the influence of the latter variable on the sign, magnitude and uncertainty of the projected yield change. It should be noted that since the meta-database includes heterogeneous results coming from various publications with very different methodologies, regions and crops, we will limit our meta-analysis to a visual comparison of the results through histograms and illustrate the main differences between studies. Indeed, as mentioned by Challinor et al. (2007), the estimation of uncertainty from a sample of several impact studies is not precise enough to provide a full quantitative assessment.

\section{Results}

Fig. 2 shows the distribution of relative yield variation under climate change for all simulations (all database, full line) and for simulations assuming no $\mathrm{CO}_{2}$ fertilization effect (dashed line). The former aims at giving a global snapshot of all the values in the literature while the latter plot focuses on climate impacts only. It reveals a large spectrum of response for both distributions even though, globally, they depict a negative pattern: the median values are $-11 \%$ without the $\mathrm{CO}_{2}$ fertilization effect and $-5 \%$ with it. In order to focus more precisely on the impacts of climate, we next consider only the yields change without the $\mathrm{CO}_{2}$ fertilization effect (190/357 points). It should be noted that all the figures described in Section 3 have also been plotted using the whole database. The comparison reveals the same global tendency. The $\mathrm{CO}_{2}$ fertilization effect will be considered separately in Section 3.6.

\subsection{Process based vs. statistical crop modeling}

We divide the meta-database without a $\mathrm{CO}_{2}$ fertilization effect into two sub-groups: studies using process-based crop models and statistical models. The distribution (Fig. 3) medians are quite close ( $-13 \%$ for process based models vs $-11 \%$ ). It means that, although

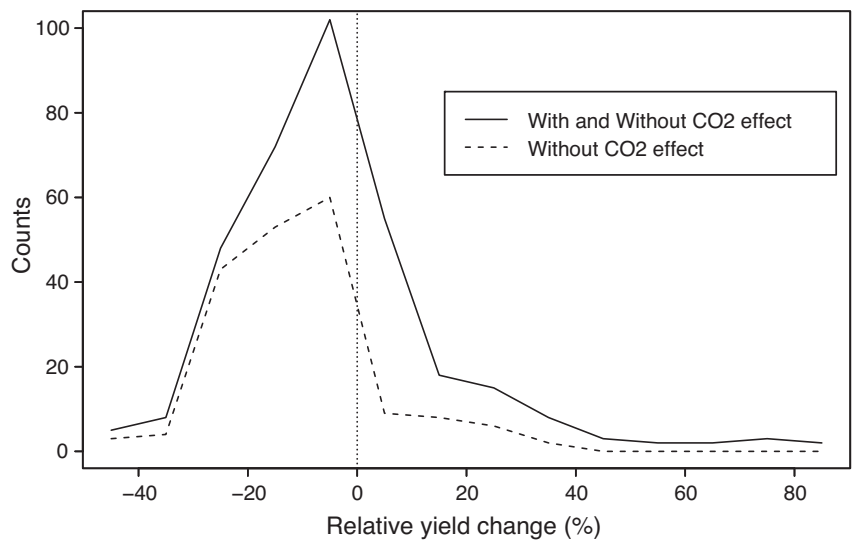

Fig. 2. Distribution of future yields according to the 16 selected studies (all countries, time horizons, crops...). The full line represents the 347 points altogether and the dashed one only the points with no $\mathrm{CO}_{2}$ fertilization (190 points).

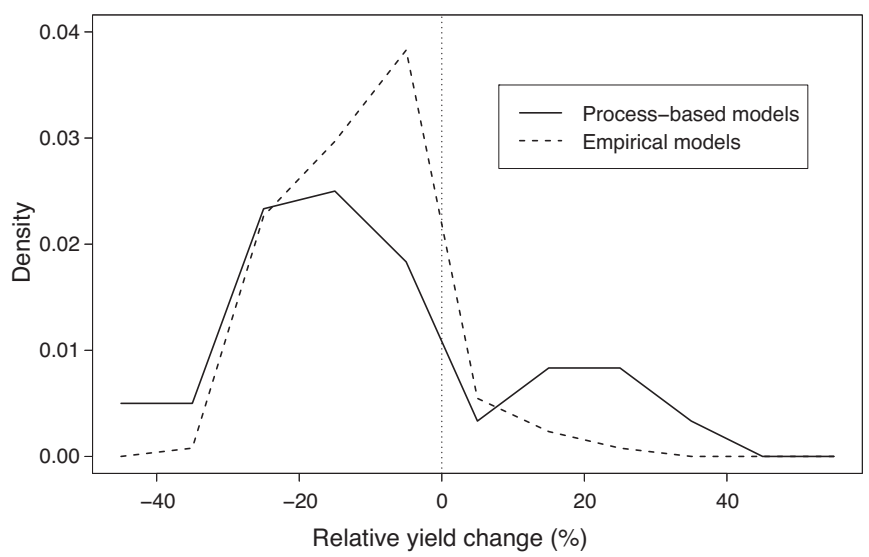

Fig. 3. Distribution of yields for studies using statistical crop models (dashed line) and for studies using process-based crop models (full line).

completely different in nature, the two methodologies give similar results for future yields. However, results from process based crop modelling studies show a larger dispersion in the yield response with yield anomalies of greater amplitude. Indeed such methods are able to capture complex non-linear yield responses resulting from multiple interactive factors $\left(\mathrm{CO}_{2}\right.$ effect, rainfall distribution changes, extreme temperature effects...) while statistical methods are much more constrained and do not accommodate drastic changes in future yields.

\subsection{Effect of the magnitude of radiative forcing}

Here the database is divided into two categories according to radiative forcing, an indicator which synthesizes the warming impact of anthropogenic greenhouse gases and aerosols. For a given climate model, radiative forcing determines the average temperature but the latter also depends on the model's climate sensitivity. Splitting the database according to radiative forcing provides an indication of the benefits of climate change mitigation. Indeed because of climate system inertia, a significant warming is unavoidable, and emission reductions can only mitigate this warming. Thus, the benefits of such reductions are better assessed by comparing the impacts of a moderate warming to that of a much greater warming, than by comparing a no-warming scenario (which is already out-of-reach) to a warming scenario. Fig. 4 shows that the yield response is quite different for the two radiative forcing categories. The impact of climate change on yield

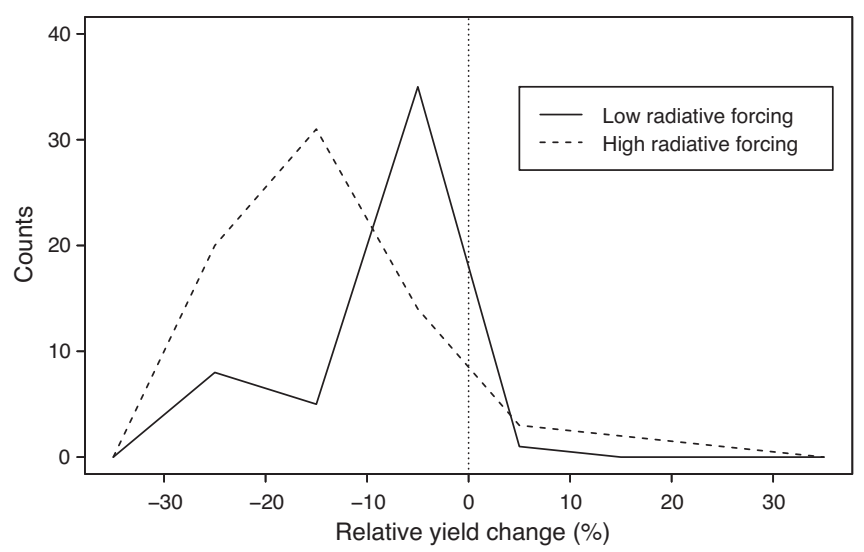

Fig. 4. Distribution of yields for two warming categories: radiative forcing $\geq 3.9 \mathrm{~W} /$ $\mathrm{m}^{2}$ (dashed line) and $<3.9 \mathrm{~W} / \mathrm{m}^{2}$ (full line). 
is clearly more negative for the higher one (median $=-15 \% \mathrm{vs}$. $-6 \%$ ). The range of values is also larger for the high radiative forcing category.

\subsection{Effect of temperature and rainfall changes}

Rainfall and temperature changes are major determinants of recently observed trends in agricultural production in Sub-Saharan Africa. Both past temperature increase and rainfall decrease have led to a production shortage since the 1970s (Barrios et al., 2008). If the effects of rainfall change overtake that of recent temperature change (Barrios et al., 2008), it might be quite different in future projections. Indeed, the IPCC (2007) projections show a temperature increase ranging from $+1.8{ }^{\circ} \mathrm{C}$ to $+4.7^{\circ} \mathrm{C}$ in WA in 2090 , for scenario $\mathrm{A} 1 \mathrm{~B}$, and a rainfall change ranging globally from $-9 \%$ to $+13 \%$, with no agreement among models on the sign of the change). As underlined by Schlenker and Lobell (2010) these temperature increases are much larger relative to precipitation changes, with the latter typically smaller than the historical standard deviation. Furthermore, they found that the marginal impact of one standard deviation change in precipitation is smaller than that of one standard deviation change in temperature.

Based on the results from Schlenker and Lobell (2010), Fig. 5 attempts to assess the respective impact of temperature and rainfall change on future yield change. Even if rainfall remains constant, the yield decreases by about $15 \%$, probably due to the effect of higher temperature reducing the crop growth cycle length and increasing water stress through higher evaporation. However, rainfall change does have an impact, even if it is lower than that due to a temperature change. Fig. 5 shows that the median yield changes when rainfall increases or decreases differ by a factor of two $-10 \%$ and $-21 \%$, respectively. However, Salack (2006) shows for a variety of millet that rainfall increase did not totally compensate for the effect of temperature increase $\left(+1.5^{\circ} \mathrm{C}\right)$ but greatly mitigated the impacts of warming ( $-59 \%$ and $-26 \%$ for decreasing and increasing rainfall, respectively). Similarly, Fischer et al. (2002) show that the production of wheat, rice and maize do not vary a lot when rainfall increases: for WA, the relative production changes for the three scenarios $+2{ }^{\circ} \mathrm{C} /+0 \%,+2{ }^{\circ} \mathrm{C} /+5 \%,+2{ }^{\circ} \mathrm{C} /+10 \%$ are respectively $-13 \%$, $-13 \%$ and $-12 \%$. However, assessing the respective roles of temperature and rainfall change on crop yield change is difficult since those two variables are closely linked, as shown by Douville et al. (2006) who demonstrates the effect of precipitation on surface temperature in the Sahel. Furthermore, effects of temperatures and

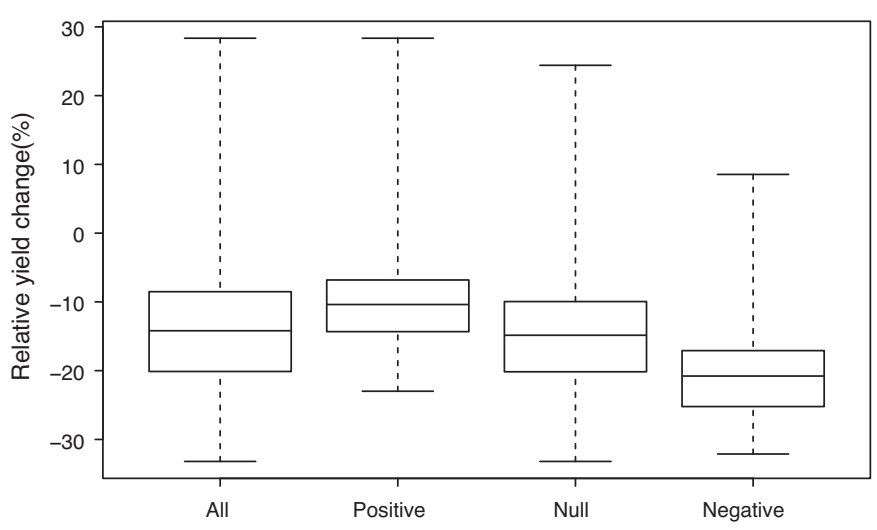

Fig. 5. Impact of rainfall on yield. "All" is the boxplot of the yields evolution for the whole study (increasing and decreasing rainfall altogether). "Positive" shows yields when rainfall increases ( $\geq 5 \%)$, "null" when rainfall does not change (]$-5 \%$; $+5 \%[)$ and "negative" when rainfall decreases $(\leq-5 \%)$ This is only based on values from Schlenker and Lobell (2010). The bold line is the median, the lower hinge is the 1st quartile, the upper hinge is the 3rd quartile and the whiskers extend to the distribution extremes.

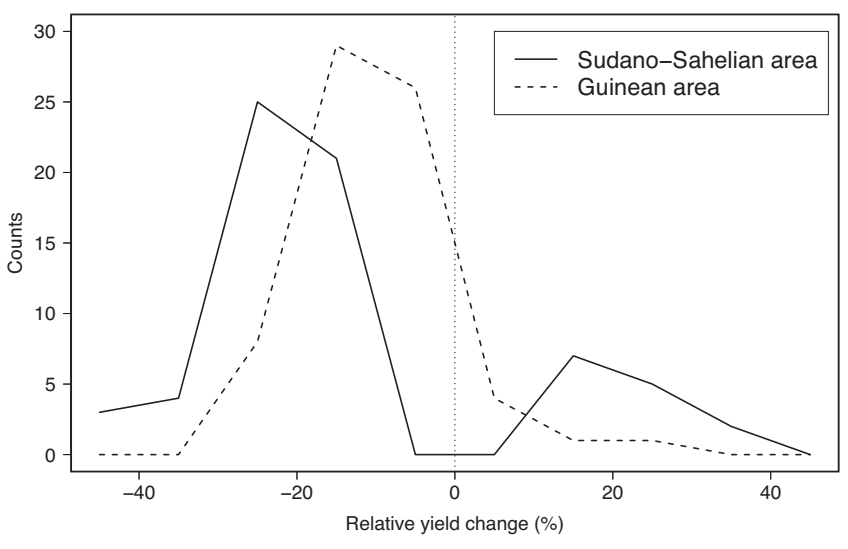

Fig. 6. Distribution of yields for the Sudano-Sahelian area (full line) and the Guinean one (dashed line).

rainfall changes can interplay. For instance, for crops, the combination of high temperatures and abundant rainfall fosters high rates of chemical weathering and leaches clay soils of low inherent fertility (Barrios et al., 2008).

\subsection{Differences between the Sudano-Sahelian and Guinean areas}

The impact of climate change on West African yields differs between the south (the Guinean zone) and the north (the SudanoSahelian zone). Fig. 6 shows the distribution of the relative yield change for countries belonging to the Guinean zone (dashed line) and to the Sudano-Sahelian zone (full line): more negative for the Sudano-Sahelian countries (median $=-18 \%$ ) than for the Guinean ones (median $=-13 \%$ ). This difference can be explained by the projections of future climate in Africa (see the maps from the IPCC AR4, 2007) which show a greater warming over continental Africa (particularly in Sahel and Sahara) while the temperatures of the Guinean zone, which are influenced by the ocean, are expected to increase more slowly. Moreover, an increase in temperature has a significant impact on water balance that is more detrimental in the Sudano-Sahelian zone, where water is often a limiting factor, than in the Guinean zone where it is not.

Interestingly, the role of rainfall seems also to be different in both areas. According to Fischer et al. (2002) the relative production changes for the three scenarios $+2{ }^{\circ} \mathrm{C} /+0 \%,+2{ }^{\circ} \mathrm{C} /+5 \%$ and $+2{ }^{\circ} \mathrm{C} /+10 \%$ are $-23 \%,-14 \%,-8 \%$ in the Sudano-Sahelian zone and $-8 \%,-12 \%,-14 \%$ in the Guinean zone. This point needs further investigations in forthcoming studies focusing only on yields.

\subsection{Differences among cultivars}

Most of the selected studies focus on one or more varieties without specifying which cultivar is used. However, in reality, farmers are able to select adapted varieties (e.g. late or early millet) or to adapt their practices (e.g. delayed or early sowing), with significant consequences on yields. For instance, Smith et al. (1996) and Salack (2006) show that future yields of millet differ strongly according to the variety $(-44 \%$ to $-29 \%$ for early millet and $-21 \%$ to $-14 \%$ for late millet). Thus, it seems very important for future studies to take into account different cultivars, or at least to carefully define the ones used in order to allow comparisons between results.

\section{6. $\mathrm{CO}_{2}$ fertilization effect}

Rising concentrations of $\mathrm{CO}_{2}$ in the atmosphere are driving global warming that will impact on crop yields through changes in rainfall and increases in temperature. However, elevated $\mathrm{CO}_{2}$ also 
has beneficial physiological effects on crops through the stimulation of photosynthesis and reduction of drought stress as a result of lower stomatal conductance and greater intercellular $\mathrm{CO}_{2}$ (Tubiello et al., 2007b; Leakey, 2009). By conducting a systematic comparison between yield response to climate change with, or without, $\mathrm{CO}_{2}$ fertilization effect, Müller et al. (2010) conclude that the largest uncertainty in the quantification of agricultural impacts is the effect of $\mathrm{CO}_{2}$. They found a yield increase of $8 \%$ in African scenarios (percent change in 2046-2055 relative to 1996-2005) with full $\mathrm{CO}_{2}$ fertilization, and a yield loss of $-8 \%$ without the $\mathrm{CO}_{2}$ effect. Similar results are found by Müller et al. (2010) at the global scale where the $\mathrm{CO}_{2}$ fertilization effect determines the sign of future yield changes. However, other studies show lower differences between full and no $\mathrm{CO}_{2}$ fertilization scenarios. Finally, the effect seems to be less important when considering short and mid-term horizons, moderate $\mathrm{CO}_{2}$ emission scenarios and $\mathrm{C} 4$ crops. For instance, Parry et al. (2004) do not find a strong difference in 2020 between $\mathrm{CO}_{2}$ fertilization and no $\mathrm{CO}_{2}$ fertilization projections, whereas the difference is much stronger in 2080.

In this section, we quantitatively study the $\mathrm{CO}_{2}$ fertilization effect, focusing only on studies that provide results with and without this effect. Fig. 7 shows that the difference between both hypotheses depends strongly on the parameters (e.g. type of crops, time horizon, emission scenario) considered. The difference is particularly high for C3 crops (e.g. soybean, groundnut) and for situations with high $\mathrm{CO}_{2}$ concentrations: typically, at the end of the century and for SRES A scenarios. Moreover, in some cases the $\mathrm{CO}_{2}$ fertilization effect may compensate the yield loss due to climatic parameters, and sometimes reverse it: this happens in 6 cases (see Fig. 7). Note that the point with no difference between no and full $\mathrm{CO}_{2}$ fertilization comes from Parry et al. (2004) who use color scales for their results. This means that both points are in the same category $([-30 \% ;-10 \%])$.

\subsection{Results on monetary variables}

Another way to analyze the impact of climate change on agriculture is to look for a statistical correlation, not between climate and agricultural physical production or yields, but between local climate (generally approximated by seasonal rainfall and temperature) and monetary variables like the value of production, farm income or agricultural land. This is the basis of the so-called "Ricardian" approach introduced by Mendelsohn et al. (1994) for the US, and since then applied to Africa, e.g. by Ajetomobi et al. (2010), Hassan (2010), Kurukulasuriya and Mendelsohn (2008, 2007), Molua (2009) and Nhemachena et al. (2010). In addition, Seo et al. (2009) recently studied the impact on agricultural revenue by combining the agro-ecological zones (AEZ) method and the Ricardian approach.

As mentioned before, we comment on the results from this approach in the present section rather than combining them with the rest of the database, since the latter results concern physical yields, not monetary variables. Moreover, in some studies, the results are not workable: they may cover Africa as a whole, or it may not be possible to compute a relative variation. The range of values in the Ricardian analysis is very important, even within a single study. For instance, according to Kurukulasuriya and Mendelsohn (2007), in 2100, income variation in Africa ranges from $-34 \%$ to $+66 \%$, depending on the GCM. For Cameroon in 2100, Molua (2009) finds a large range of values, from $-50 \%$ to $+37.5 \%$, depending on the GCM used (with SRES B2 scenario). Similar contrasted results are also found in Hassan (2010) and Seo et al. (2009). This dispersion may be due to differences in GCMs projections and also due to the sensitivity of the Ricardian analysis to rainfall. Indeed, Ajetomobi et al. (2010) show with rice in Nigeria, that a 5\% decrease in rainfall leads to a $65.35 \%$ decrease in income on nonirrigated farms, although $+2{ }^{\circ} \mathrm{C}$ leads only to $-11.7 \%$. Moreover,

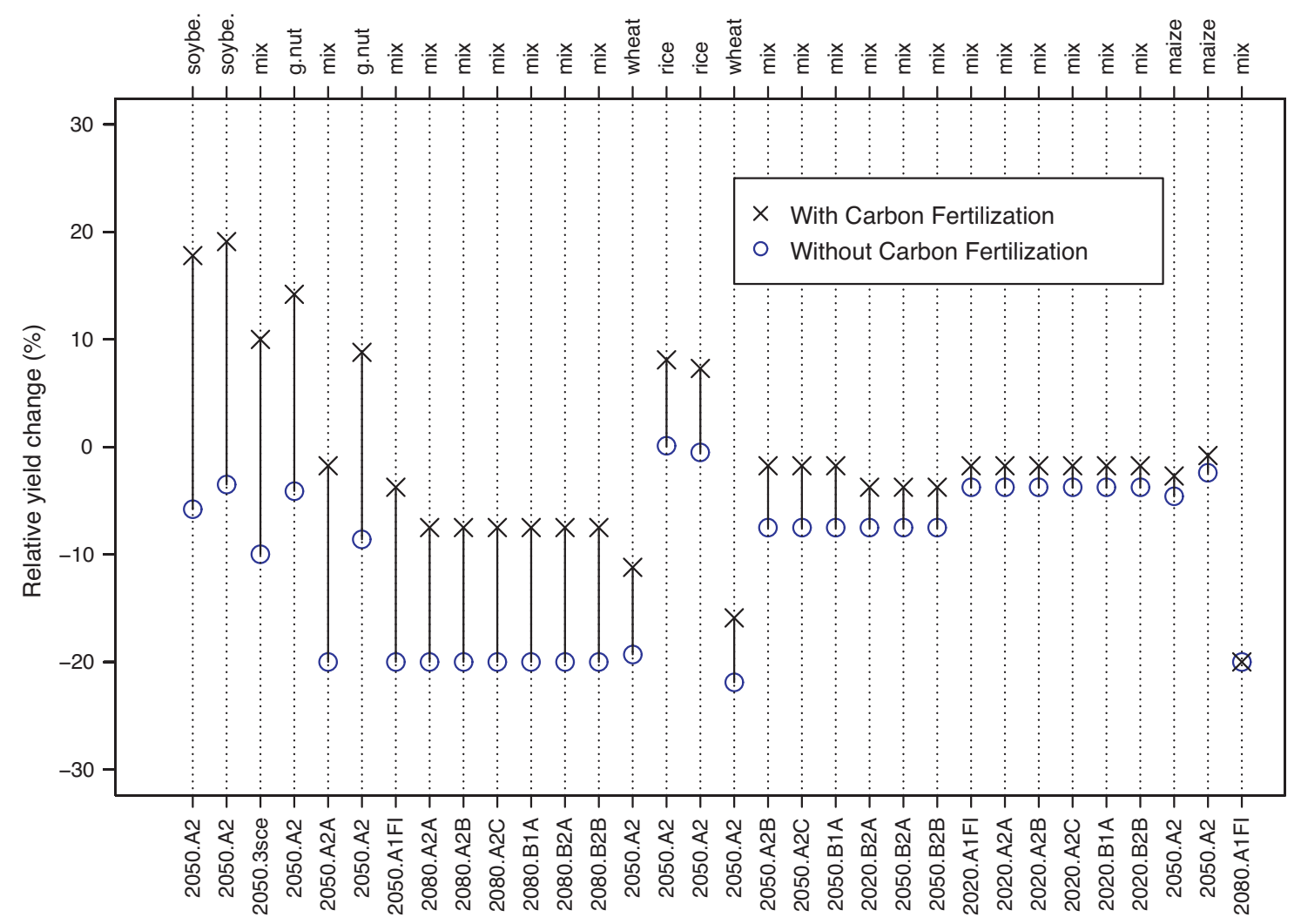

Fig. 7. Relative yield change differences between full and no $\mathrm{CO}_{2}$ fertilization within a study. "Mix" is for a mix of crops ("cereals" or "major crops"). 
the Ricardian approach may forecast in some cases more positive changes than both other methodologies because it assumes full adaptation.

Because of this wide range of values, it is not yet possible to reach a conclusion on future trends from these Ricardian studies.

\section{Conclusions}

Quantifying the impacts of climate change on agriculture is a challenging task because of large uncertainties in regional climate change projections, in the response of crop to environmental changes (rainfall, temperature, $\mathrm{CO}_{2}$ concentration), in the coupling between climate models and crop productivity functions, and in the adaptation of agricultural systems to progressive climate change.

Quantifying such impacts requires a nested methodology where basic assumptions (for instance, the choice of the climate model and/or the crop model) can strongly influence the sign and magnitude of yield response. So, to extract a robust signal of climate change impact, it is necessary to sample several methods and scenarios. By combining results from 16 published papers, this study gives an overview of the sign, amplitude and uncertainty of impacts on crop productivity in West Africa. In spite of a large dispersion of future yield changes, ranging from a yield loss of $-50 \%$ to a yield increase of $+90 \%$, the median value gives a negative yield loss near $-11 \%$. This negative impact seems robust since it is found from both empirical and process-based crop models, although the uncertainty is far larger for processbased studies. Dry cereals cultivated in Sudano-Sahelian countries will be more affected by climate change (median $=-18 \%$ ) than those cultivated in Guinean countries (median $=-13 \%$ ). We found that the negative impacts of climate change on crop productivity are more severe with more intense warming scenarios, with a median yield loss near $-15 \%$ for the most intense warming scenarios. This relationship between warming intensity and climate impacts highlights the positive effect of climate change mitigation: mitigating global warming will result in less severe impacts.

The consistent negative impact of climate change on crop yield emerging from the 16 studies database results partly from a temperature rise that reduces the crop cycle duration and creates higher water stress through higher evapotranspiration demand. Rainfall changes have the potential to aggravate or mitigate this negative impact, whether rainfall decreases or increases in the future. However, despite the importance of rainfall on crop yield in traditional rainfed systems in Africa, future scenarios of WAM changes are divergent among the IPCC climate models. Thus, producing reliable future scenarios of agricultural productivity depends critically on the ability of the climate modelling community to reduce the uncertainties in climate change projections (rainfall and temperature).

Our meta-analysis highlights the pivotal role that the $\mathrm{CO}_{2}$ fertilization effect has on the sign and amplitude of changes in crop yield response to climate change. While the impact of climate change on crop yield is essentially negative without considering the fertilization effect of $\mathrm{CO}_{2}$, future yields scenarios accounting for this effect are more optimistic. However the $\mathrm{CO}_{2}$ effect is difficult to estimate accurately and to parameterize in crop models (Long et al., 2006; Tubiello et al., 2007a; Ainsworth et al., 2008b; Müller et al., 2010) and the recent review of Leakey (2009) consider that $\mathrm{CO}_{2}$-induced yield increase is likely to be overly optimistic in current projections of future crop yields. It is particularly true for C4 plants (mainly sorghum, maize, millet in Africa) whose photosynthesis does not seem to be stimulated directly by elevated $\mathrm{CO}_{2}$ (Ghannoum et al., 2000; Leakey, 2009). Moreover, the quality of agricultural products is likely to decrease under increased $\mathrm{CO}_{2}$ fertilization with the decrease of the protein content (Taub et al., 2008) and an increased susceptibility to insect pests (e.g. Dermody et al., 2008; Zavala et al., 2008). It is, therefore, crucial to improve our knowledge of the effect of $\mathrm{CO}_{2}$ on $\mathrm{C} 4$ crops in order to achieve better reliability in future crop yields in West Africa.

Another type of study, Ricardian studies, assumes full adaptation and focuses on the value of farmland or farm income (and not on yields): that is why we present their results separately. Moreover, the selected Ricardian studies sometimes give results for Africa as a whole. These papers show a large dispersion of excepted impacts, even within one study. That is why it is not yet possible to use these studies to reach a conclusion on future trends.

Finally, as mentioned by Challinor et al. (2007), direct comparison among studies dealing with climate change and agricultural impacts is a difficult task. These studies encompass a range of different countries, scales and crops, and uncertainty can come from various sources (climate models and scenarios, crop models, downscaling). Hence combining yield impact studies is a first step in the estimation of sign, magnitude and uncertainty of climate change impacts, but is not sufficiently precise. The multi-ensembles approach, with varying climate models, emissions scenarios, crop models (including different set of parameterizations for crucial processes), and downscaling techniques, as recommended by Challinor et al. (2007), would enable a move towards a more complete sampling of uncertainty in crop yield projections. Among those parameters, it may be particularly interesting to focus on differences between crop models and between downscaling methods. Indeed, the uncertainty created by these parameters has rarely been studied although, for hydrological impacts, Mall et al. (2007) show, for India, substantial differences between dynamical crop models, and Ducharne et al. (2009) important differences between downscaling methods. Conducting such a multi-ensembles approach for assessing the impacts of climate change on agriculture in Africa is particularly relevant in the framework of the coming IPCC exercise.

\section{Acknowledgements}

This work is part of the REGYNA project (http://www.gisclimat.fr/en/project/regyna), supported by the ParisClimate-Environment-Society consortium (http://www.gisclimat.fr/en) and was also funded by the R2DS network. We would like to thank all authors of the papers selected in this review for their work and especially David Lobell for providing detailed results of his study. Moreover, we thank the PCMDI team for providing useful freeaccess data.

\section{Appendix A. Supplementary data}

Supplementary data associated with this article can be found, in the online version, at doi:10.1016/j.gloenvcha.2011.04.007.

\section{References}

Adejuwon, J.O., 2006. Food crop production in Nigeria. II. Potential effects of climate change. Climate Research 32, 229-245.

Ajetomobi, J.O., Abiodun, A., Hassan, R., 2010.In: Economic impact of climate change on rice agriculture in Nigeria. Joint 3rd African Association of Agricultural Economists (AAAE) and 48th Agricultural Economists Association of South Africa (AEASA) Conference, Cape Town, South Africa, September 1923, 2010.

Ainsworth, E.A., Leakey, A.D.B., Ort, D.R., Long, S.P., 2008. FACE-ing the facts: inconsistencies and interdependence among field, chamber and modeling 
studies of elevated $\left[\mathrm{CO}_{2}\right]$ impacts on crop yield and food supply. New Phytologist $179,5-9$.

Barrios, S., Ouattara, B., Strobl, E., 2008. The impact of climatic change on agricultural production: is it different for Africa? Food Policy 33, 287-298.

Ben Mohamed, A., Vanduivenbooden, N., Abdousallam, S., 2002. Impact of climate change on agricultural production in the Sahel-Part1. Methodological approach and case study for millet in Niger. Climatic Change 54, 327-348.

Berg, A., Sultan, B., de Noblet, N., 2011. Including tropical croplands in a terrestrial biosphere model: Application to West Africa. Climatic Change 104, 755-782.

Biasutti, M., Sobel, A.H., 2009. Delayed Sahel rainfall and global seasonal cycle in a warmer climate. Geophysical Research Letters 36, L23707, doi:10.1029/ 2009GL041303.

Bondeau, A., Smith, P., Zaehle, S., Schaphoff, S., Lucht, W., Cramer, W., Gerten, D., Lotze-Campen, H., Müller, C., Reichstein, M., Smith, B., 2007. Modelling the role of agriculture for the 20th century global terrestrial carbon balance. Global Change Biology 13, 679-706.

Butt, T., McCarl, B., Angerer, J., Dyke, P., Stuth, J., 2005. The economic and food security implications of climate change in Mali. Climatic Change 68, 355-378.

Consultative Group on International Agricultural Research (CGIAR), 2009. Climate, Agriculture and Food Security: A Strategy for Change. CGIAR, p. 56.

Challinor, A., Wheeler, T., Garforth, C., Craufurd, P., Kassam, A., 2007. Assessing the vulnerability of food crop systems in Africa to climate change. Climatic Change 83, 381-399.

Challinor, A.J., Ewert, F., Arnold, S., Simelton, E., Fraser, E., 2009. Crops and climate change: progress, trends, and challenges in simulating impacts and informing adaptation. Journal of Experimental Botany 60, 2775-2789.

Challinor, A.J.T.R., Slingo, W., Craufurd, J.M., Grimes, P.Q.I.F., 2004. Design and optimisation of a large-area process-based model for annual crops. Agricultural and Forest Meteorology 124, 99-120.

Chuku, C.A., Okoye, C., 2009. Increasing resilience reducing vulnerability in subSaharan African agriculture: strategies for risk coping and management. African Journal of Agricultural Research 4, 1524-1535.

Commission of the European Communities, 2007. Adapting to Climate Change in Europe-Options for EU Action, Brussels, Belgium.

Dai, A., Lamb, P.J., Trenberth, K.E., Hulme, M., Jones, P.D., Xie, P., 2004. The recent Sahel drought is real. International Journal of Climatology 24 1323-1331.

De Noblet-Ducoudré, N., Gervois, S., Ciais, P., Viovy, N., Brisson, N., Seguin, B., Perrier, A., 2004. Coupling the soil-vegetation-atmosphere-transfer scheme ORCHIDEE to the agronomy model STICS to study the influence of croplands on the European carbon and water budgets. Agronomie 24, 397-407.

Dermody, O., O'Neill, B.F., Zangerl, A.R., Berenbaum, M.R., DeLucia, E.H., 2008. Effects of elevated $\mathrm{CO}_{2}$ and $\mathrm{O}-3$ on leaf damage and insect abundance in a soybean agroecosystem. Arthropod-Plant Interactions 2, 125-135.

Dingkuhn, M., Singh, B.B., Clerget, B., Chantereau, J., Sultan, B., 2006. Past, present and future criteria to breed crops for water-limited environments in West Africa. Agricultural Water Management 80, 241-261.

Douville, H., Salas-Mélia, D., Tyteca, S., 2006. On the tropical origin of uncertainties in the global land precipitation response to global warming. Climate Dynamics 26, 367-385.

Douville, H., 2008. Detection-attribution of global warming at the regional scale: how to deal with precipitation variability? Geophysical Research Letters 33, L02701, doi:10.1029/2005GL024967.

Druyan, L.M., 2010. Studies of 21st-century precipitation trends over West Africa. International Journal of Climatology Online.

Ducharne, A., Habets, F., Déqué, M., Evaux, L., Hachour, A., Lepaillier, A., Lepelletier, T., Martin, E., Oudin, L., Pagé, C., Ribstein, P., Sauquet, E., Thiéry, D., Terray, L., Viennot, P., Boé, J., Bourqui, M., Crespi, O., Gascoin, S., Rieu, J., 2009.In: Projet RExHySS: Impact du changement climatique sur les Ressources en eau et les Extrêmes Hydrologiques dans les bassins de la Seine et la Somme. Ministère de l'Ecologie, de l'Energie, du Développement durable et de la Mer, Paris, France.

Fischer, G., Shah, M., Tubiello, F.N., van Velhuizen, H., 2005. Socio-economic and climate change impacts on agriculture: an integrated assessment, 1990-2080. Philosophical Transactions on Royal Society B 360, 2067-2083.

Fischer, G., van Velthuizen, H., Shah, M., Nachtergaele, F., 2002. Global Agroecological Assessment for Agriculture in the 21st Century: Methodology and Results. International Institute for Applied Systems Analysis, Viena, 119 pp.

Ghannoum, O., von Caemmerer, S., Ziska, L.H., Conroy, J.P., 2000. The growth response of $\mathrm{C} 4$ plants to rising atmospheric $\mathrm{CO}_{2}$ partial pressure: a reassessment. Plant, Cell and Environment 23, 931-942.

Hassan, R.M., 2010. Implications of climate change for agricultural sector performance in Africa: policy challenges and research agenda. Journal of African Economies 19, ii77-ii105.

International Panel on Climate Change (IPCC), 2007. In: Core Writing Team, Pachauri, R.K., Reisinger, A. (Eds.), Contribution of Working Groups I, II and III to the Fourth Assessment Report of the Intergovernmental Panel on Climate Change. IPCC, Geneva, Switzerland, p. 104.

Jones, P.G., Thornton, P.K., 2003. The potential impacts of climate change on maize production in Africa and Latin America in 2055. Global Environmental Change 13, 51-59.

Kurukulasuriya, P., Mendelsohn, R., 2007. A Ricardian Analysis of the Impact of Climate Change on African Cropland. Policy Research Working Paper 4305.

Kurukulasuriya, P., Mendelsohn, R., 2008. A Ricardian analysis of the impact of climate change on African cropland. AfJARE 2 (1), 1-23.
Leakey, A.D.B., 2009. Rising atmospheric carbon dioxide concentration and the future of C4 crops for food and fuel. Proceedings of Royal Society B 276, 2333-2343.

Liu, J., Fritz, S., van Wesenbeeck, C.F.A., Fuchs, M., You, L., Obersteiner, M., Yang, H., 2008. A spatially explicit assessment of current and future hotspots of hunger in Sub-Saharan Africa in the context of global change. Global and Planetary Change 64, 222-235.

Lobell, D.B., Burke, M.B., Tebaldi, C., Mastrandrea, M.D., Falcon, W.P., Naylor, R.L., 2008. Prioritizing climate change adaptation needs for food security in 2030. Science 319, 607-610.

Long, S.P., Ainsworth, E.A., Leakey, A.D.B., Morgan, P.B., 2006. Food for thought: lower-than-expected crop yield stimulation with rising $\mathrm{CO}_{2}$ concentrations. Science 312, 1918-1921.

Mall, R., Singh, R., Gupta, A., Srinivasan, G., Rathore, L., 2007. Impact of climate change on Indian agriculture: a review. Climatic Change 82, 225-231.

Mendelsohn, R., Nordhaus, W.D., Shaw, D., 1994. The impact of global warming on agriculture: a Ricardian analysis. American Economic Review 84, 753-771.

Molua, E.L., 2009. An empirical assessment of the impact of climate change on smallholder agriculture in Cameroon. Global and Planetary Change 67, 205-208.

Müller, C., Bondeau, A., Popp, A., Waha, K., Fader, M., 2010. Climate change impacts on agricultural yields. Background note to the World Development Report 2010. Potsdam Institute for Climate Impact Research, Potsdam.

Nelson, G.C., Rosegrant, M., Koo, J., Robertson, R., Sulser, T., Zhu, T., Msangi, S., Ringler, C., Palazzo, A., Batka, M., Magalhaes, M., Lee, D., 2009. Climate Change: Impact on Agriculture and Costs of Adaptation. International Food Policy Research Institute, Washington, DC.

Nhemachena, C., Hassan, R., Kurukulasuriya, P., 2010. Measuring the economic impact of climate change on African agricultural production systems. Climate Change Economics 1 (1), 33-55.

Paeth, H., Capo-Chichi, A., Endlicher, W., 2008. Climate Change and food security in tropical West Africa: a dynamic-statistical modelling approach. Erdkunde 62, 101-115.

Paeth, H., Hall, N.M.J., Gaertner, M.A., Dominguez Alonso, M., Moumouni, S., Polcher J., Ruti, P.M., Fink, A.H., Gosset, M., Lebel, T., Gaye, A.T., Rowell, D.P., MoufoumaOkia, W., Jacob, D., Rockel, B., Giorgi, F., Rummukainen, M., 2011. Progress in regional downscaling of West African precipitation. Atmospheric Science Letters $12,75-82$

Parry, M.L., Rosenzweig, C., Iglesias, A., Livermore, M.G.F, 2004. Effects of climate change on global food production under SRES emissions and socio-economic scenarios. Global Environmental Change 14, 53-67.

Patricola, C.M., Cook, K.H., 2010. Northern African climate at the end of the twentyfirst century: an integrated application of regional and global climate models. Climate Dynamics 35, 193-212.

Randall, D.A., Wood, R.A., Bony, S., Colman, R., Fichefet, T., Fyfe, J., Kattsov, V., Pitman, A., Shukla, J., Srinivasan, J., Stouffer, R.J., Sumi, A., Taylor, K.E., 2007. Climate models and their evaluation. In: Solomon, S., Qin, D., Manning, M., Chen, Z., Marquis, M., Averyt, K.B., Tignor, M., Miller, H.L. (Eds.), Climate Change 2007: The Physical Science Basis. Contribution of Working Group I to the Fourth Assessment Report of the Intergovernmental Panel of Climate Change.. Cambridge University Press, Cambridge, U.K.

Salack, S., 2006. Impacts des changements climatiques sur la production du mil et du sorgho dans les sites pilotes du plateau central, de Tahoua et de Fakara. CILSS, Niamey, Niger.

Schlenker, W., Lobell, D.B., 2010. Robust negative impacts of climate change on African agriculture. Environmental Research Letters 5, 1-8.

Seo, S.N., Mendelsohn, R., Dinar, A., Hassan, R., Kurukulasuriya, P., 2009. A Ricardian analysis of the distribution of climate change impacts on agriculture across agro-ecological zones in Africa. Environmental \& Resource Economics 43, 313-332.

Smith, J.B., Huq, S., Lenhart, S., Mata, L.J., Nemesova, I., Toure, S., 1996. Vulnerability and Adaptation to Climate Change: Interim Results from the U.S. Country Studies Program. Kluwer Academic Publishers.

Tao, F., Zhang, Z., Liu, J., Yokozawa, M., 2009. Modelling the impacts of weather and climate variability on crop productivity over a large area: a new super-ensemble-based probabilistic projection. Agricultural and Forest Meteorology 149, 1266-1278.

Taub, D., Miller, B., Allen, H., 2008. Effects of elevated $\mathrm{CO}_{2}$ on the protein concentration of food crops: a meta-analysis. Global Change Biology 14 565-575.

Tingem, M., Rivington, M., 2009. Adaptation for crop agriculture to climate change in Cameroon: turning on the heat. Mitigation and Adaptation Strategies for Global Change 14, 153-168.

Trenberth, K.E., Jones, P.D., Ambenje, P., Bojariu, R., Easterling, D., Klein Tank, A. Parker, D., Rahimzadeh, F., Renwick, J.A., Rusticucci, M.B.S., Zhai, P., 2007. Observations: surface and atmospheric climate change. In: Solomon, S., Qin, D., Manning, M., Chen, Z., Marquis, M., Averyt, K.B., Tignor, M., HL, M. (Eds.), Climate Change 2007: The Physical Science Basis. Contribution of Working Group I to the Fourth Assessment Report of the Intergovernmental Panel on Climate Change. Cambridge University Press, Cambridge, pp. 235336.

Tubiello, F.N., Amthor, J.S., Boote, K.J., Donatelli, M., Easterling, W., Fischer, G., Gifford, R.M., Howden, M., Reilly, J., Rosenzweig, C., 2007. Crop response to elevated $\mathrm{CO}_{2}$ and world food supply: a comment on "Food for Thought." by Long et al., Science 312:1918-1921, 2006. European Journal of Agronomy 26 215-223. 
Tubiello, F.N., Soussana, J.F., Howden, M., 2007. Crop and pasture response to climate change. PNAS 104, 19686-19690.

Vanduivenbooden, N., Abdousallam, S., Ben Mohamed, A., 2002. Impact of climate change on agricultural production in the Sahel-Part 2. Case study for groundnut and cowpea in Niger. Climatic Change 54, 349-368.

World Bank, 2008. Reports on Environment issues by World Bank's Vulnerability and Adaptation, Climate Change and Poverty units.
Zavala, J.A., Casteel, C.L., DeLucia, E.H., Berenbaum, M.R., 2008. Anthropogenic increase in carbon dioxide compromises plant defense against invasive insects. Proceedings of the National Academy of Sciences of the United States of America $105,5129-5133$.

Zorita, E., von Storch, H., 1999. The analog method-a simple statistical downscaling technique: comparison with more complicated methods. Journal of Climate 12, 2474-2489. 